\title{
What artificial intelligence may, or may not, contribute to human ARTs
}

\author{
David F. Albertini ${ }^{1}$ \\ Published online: 6 October 2020 \\ (C) Springer Science+Business Media, LLC, part of Springer Nature 2020
}

For a medical subdiscipline with only a four decade history, human ARTs has had its share of trials and tribulations. As we approach the 10 million mark of ART produced members of our species, it is no surprise to many that emergent technologies looking for a home in the practice of reproductive medicine are coming to occupy their niche both within and without the formal setting of IVF clinics. With the disruptive year of 2020 drawing to completion, it behooves all in our disciplinestakeholders, scientists and clinicians-to examine our role in delivering patient care of the highest standards possible.

The now apparent transient epidemic of multiple births seems to be coming under control with the advent and adoption of single embryo transfer. Over the years, the unnatural (iatrogenic) cause of the multiple gestation epidemic in human ARTs as practiced through these decades drew from a singular objective: to obtain as many embryos as possible to transfer by pushing the limits of ovarian stimulation as far as tolerable. More stim translated into more eggs, more embryos, more pregnancies and wishfully more babies-maybe!

But now comes the rub. Despite the ramping up of number of embryos transferred, and the associated increase in pregnancy rates, only a small fraction of the oocytes retrieved result in a live birth. This apparent inefficiency viewed as an input-output measure is understandably confounded by many factors not the least of which is the limitation imposed by we hominids on being hominids! Beyond the intangible evolutionary imperative comes the hope, if not directive, to find a way to select embryos with the best chances of implanting and surviving to term. Enter artificial intelligence.

The first of several accounts and evaluations for how AI has and will continue to impact the practice of human ARTs is featured this month. We begin with the account of Fernandez and colleagues in a cross discipline treatment of AI breaking down basic elements of the approach and rendering the subject for those of us unfamiliar with basic principles and practices (Artificial intelligence in the IVF laboratory: overview through the application of different types of algorithms for the classification of reproductive data, https://doi.org/10.1007/ s10815-020-01881). This is followed by the commentary by Curchoe casting a reality check on the matter at hand (All Models Are Wrong, but Some Are Useful, https://doi.org/ 10.1007/s10815-020-01895). before wandering aimlessly into the jungle of nifty new gimmicks that we in the business of human ARTs have been prone to repeatedly over our relatively short time in the biomedical enterprise. The subjects of AI and the utility of models of various kinds will be revisited in upcoming issues and these contributions will hopefully serve to both introduce and engage our readership in what lies ahead.

Finally, we continue our coverage of the COVID-19 pandemic as viewed through the lens of the practical dimension of laboratory practice (Cryopreservation and IVF in the time of Covid-19: what is the best good tissue practice (GTP)?, https://doi.org/10.1007/s10815-020-01904) and some of the expected and unexpected coincidences the pandemic has given us pause to consider during these uncertain times (A surprising link with unexplained infertility: a possible Covid-19 paradox?; SARS-CoV-2 and the next generations: which impact on reproductive tissues?). As always, your input is welcomed on our treatment of the various aspects of reproductive medicine influencing our current practices and future hopes for the field. Stay well!

Publisher's note Springer Nature remains neutral with regard to jurisdictional claims in published maps and institutional affiliations.
David F. Albertini

eicjarg@gmail.com

1 Bedford Research Foundation, Bedford, MA, USA 